
\title{
(1)
}

\section{Tunable Photoluminescence via Thermally Evaporated ZnS Ultra Thin Films}

\author{
Yoshifumi Urakawa ${ }^{\mathrm{a}, \mathrm{b},{ }^{*}}$ and Karen K. Gleason ${ }^{\mathrm{b}}$ \\ ${ }^{a}$ Institute for Polymers and Chemicals, Business Development Center, Showa Denko K. K., Kawasaki, Kanagawa 210-0867 \\ Japan \\ ${ }^{b}$ Department of Chemical Engineering, Massachusetts Institute of Technology, Cambridge, MA 02139, USA
}

\begin{abstract}
ZnS thin films have been deposited by thermal evaporation at various deposition rates. By controlling the deposition rate, the position of the maximum in the photoluminescence spectra could be easily tuned from 2.9 to $2.0 \mathrm{eV}$, which produced a corresponding change in the emission color. The optical and morphological characteristics of the ZnS thin films were measured. The photoluminescence spectra had broad peaks, suggesting a distribution of ZnS nanocrystallites dimensions. Nanocrystallites dimensions were in the range of $1 \mathrm{~nm}$ to $3 \mathrm{~nm}$ via TEM analyses. The changes in optical properties were potentially attributable to the lattice defects of ZnS crystals, including Schottky defects and the substation of sulfur atoms by oxygen atoms. The color of the resulting light emission was obtained by controlling the deposition rate of $\mathrm{ZnS}$.
\end{abstract}

Received on 20-03-2014 Accepted on 25-04-2014 Published on 25-06-2014

Keywords: Zinc Sulfide, Thermal Evaporation, Thin Film, Photoluminescence, Lattice Defect.

\section{INTRODUCTION}

A single material with tunable optical properties would be desirable and useful for applications including displays, photovoltaics, solid state lighting and computing. Quantum dots are semiconductors whose electric characteristics are related to its grain size and shape of the individual crystal. There is a significant relationship between the grain size and band gap [1]. As the grain size increases, the band gap increases. This variability of band gap enables control over the absorbance and emission spectra of quantum dots. We focus on Zinc Sulfide (ZnS), due to its unique optical properties and stability. Bulk ZnS is a II-VI semiconductor with large band gap energy of $3.72 \mathrm{eV}$ for cubic zinc blende structure and $3.77 \mathrm{eV}$ for hexagonal wurtzite structure at room temperature [2]. In addition, $\mathrm{ZnS}$ is relatively inexpensive and nontoxic material, which is favorable for transition to industry. Many techniques have been reported for the synthesis of $\mathrm{ZnS}$ particles and films [3-5]. Thin films of ZnS has been deposited by thermal evaporation [6, 7], sputtering [8], molecular beam epitaxy [9], chemical bath deposition [10] and spray pyrolysis [11]. Among these processes, thermal evaporation is attractive technique in terms of the ease of controlling the deposition rate and applicability for various substrates.

"5-1, Ogimachi, Kawasaki-Ku, Kawasaki, Kanagawa 210-0867 Japan; Tel: +81-44-322-6930; Fax: +81-44-322-6935;

E-mail: urakawa.yoshifumi.xhkua@showadenko.com
In this paper, we report the thermal evaporation and characterizations study of ZnS ultra thin films, whose thickness ranged from $3.2 \mathrm{~nm}$ to $3.9 \mathrm{~nm}$ by the measurement of ellipsometer. These nanolayers were thermally evaporated from bulk ZnS powder. By controlling the deposition rate, changes in the band structure shifted the photoluminescence response. These thin films were characterized in terms of their optical properties and morphological structure.

\section{EXPERIMENTAL DETAILS}

ZnS with $99.99 \%$ purity was purchased from Aldrich and used it without further purification. ZnS thin films were deposited on plain glass substrates in vacuum chamber of thermal evaporator (NANO-MASTER Inc., NTE-3500). The vacuum chamber was maintained at a pressure of $10^{-6}$ torr to deposit the ZnS thin films with desired deposition rate. The temperature of substrates was kept at room temperature. The film thickness was monitored by quartz crystal sensor. The only parameter varied was the targeted growth rate which was achieved by variation of the temperature of the $\mathrm{ZnS}$ evaporation boat. The sputtering process was performed in the same vacuum chamber in order to confirm the difference of the $\mathrm{ZnS}$ thin films fabrication.

The photoluminescence $(\mathrm{PL})$ spectra were measured using spectrofluorometer (Horiba Jobin Yvon, Fluorolog-3) with 
excited at a wavelength of $365 \mathrm{~nm}$. The absorption spectra were measured by UV-Vis spectrometer (Varian, Cary 6000i). The structural analyses were performed using atomic force microscopy (AFM) (Veeco, Nanoscope $V$ with Dimension 3100), transmission electron microscopy (TEM) (JEOL, 2100FEG TEM, 200kV acceleration voltage) and attaching energy dispersive spectrometer (EDS) (Oxford, X-Max $80 \mathrm{~mm}^{2}$ EDX system).

\section{RESULTS AND DISCUSSION}

In the deposition process for $\mathrm{ZnS}$, dissociation and fractionating occurred as heating the ZnS. Zinc and sulfur vapor were generated following the reaction (1) [12].

$2 \mathrm{ZnS} \rightarrow 2 \mathrm{Zn}+\mathrm{S}_{2}(1)$

These vapors recombined to form ZnS nanocrystallites on the substrate. By varying the resistive heating of the source crucibles, the deposition rate of $\mathrm{ZnS}$ was controlled over the range from $0.05 \AA / s$ to $0.25 \AA / s$. Thin films emitting red with small photoluminescence energy were obtained as the deposition rate decreased. On the other hand, broad peaks with blue emission were obtained at higher deposition rates. We hypothesize that when the deposition rate was slow, the nucleation rate was also low due to the low density of zinc and sulfur atoms on the substrate. These atoms could migrate, leading to the growth of large crystal domains. Conversely, the crystal domains remained small at the high deposition rate because many nuclei were produced over the substrate.

Figure 1a shows the photoluminescence image of $\mathrm{ZnS}$ thin films under UV irradiation with the wavelength of $365 \mathrm{~nm}$. Various color emissions of the $\mathrm{ZnS}$ thin films were obtained. This means that controlling deposition rate enables a desired color to be obtained within the visible range from blue to red. In comparison, the $\mathrm{ZnS}$ thin films deposited by sputtering had no emission within the visible range (data not shown), which indicated that there were significant difference between morphological and crystal structures by each deposition method.

Figure 1b shows the photoluminescence spectra of the $\mathrm{ZnS}$ thin films under UV irradiation of the wavelength of $365 \mathrm{~nm}$. The film A had a main peak at $426 \mathrm{~nm}$ which was related to the blue emission. The film $B$ had a green emission with the emission center at $521 \mathrm{~nm}$ wavelength. The main peak of the $\mathrm{ZnS}$ thin film with red emission was located at $613 \mathrm{~nm}$. All peaks were broad, including the impurity peaks, which meant that deposited ZnS particles had a distribution of sizes.

Figure 1c shows the UV-Vis spectra of ZnS thin films. In the previous reports, semiconductor nanocrystallites have discrete and crystal size dependent UV-Vis absorption characteristics due to quantum confinement effect [13]. Namely, ZnS with larger band gap energy, which showed blue emission, had an absorption edge with shorter wavelength. On Figure 1c, Film A with blue emission had an absorption edge with $402 \mathrm{~nm}$, on the contrary, Film B with green emission and Film $C$ with red emission had the edges at $456 \mathrm{~nm}$ and $461 \mathrm{~nm}$ respectively. Therefore, Film B and Film $C$ had very close absorption edges, which indicated these ZnS films did not follow only quantum confinement effect. In addition, the broad spectra composed of some absorption peaks have been seen in the UV-Vis spectra due to the size distribution of $\mathrm{ZnS}$ nanocrystallites [14].

(a)

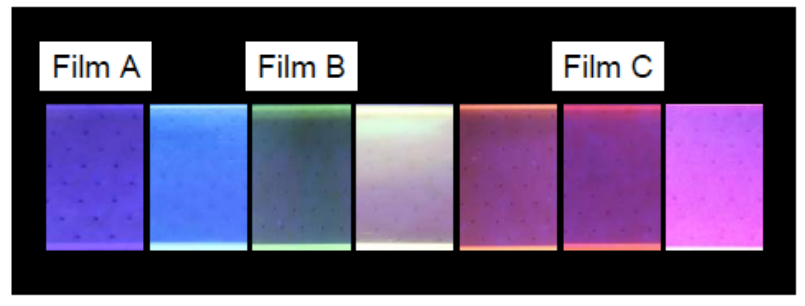

(b)

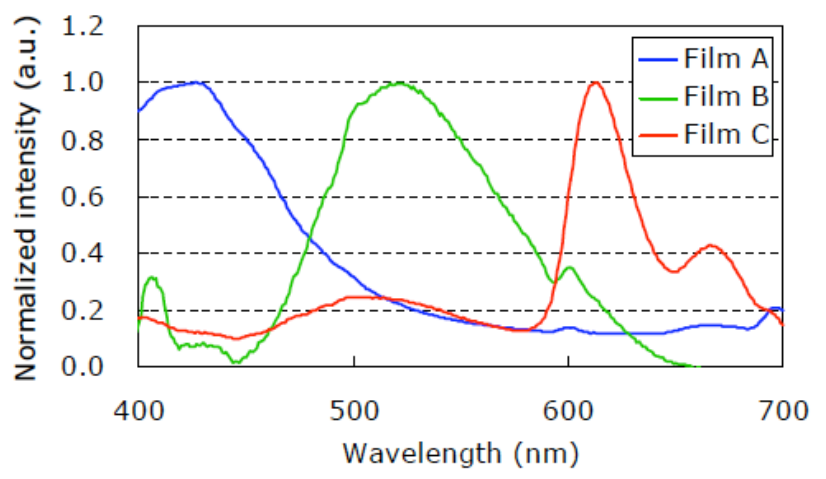

(c)

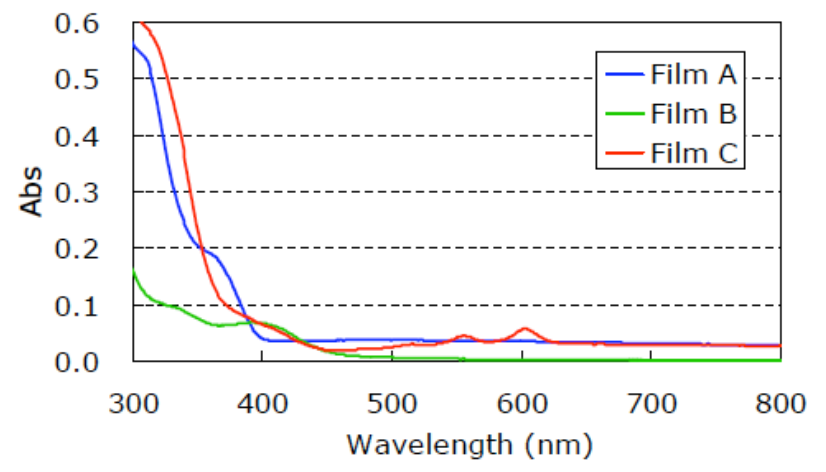

Figure 1: (a) Photoluminescence of ZnS thin films under UV irradiation, (b) photoluminescence spectra of ZnS thin films, (c) UVVis absorption spectra of ZnS thin films.

Table 1: Deposition Condition and Characteristics of ZnS Thin Films

\begin{tabular}{|c|c|c|c|}
\hline \multirow{2}{*}{ Films } & Deposition Rate & \multicolumn{2}{|c|}{ Maximum PL } \\
\cline { 2 - 4 } & $\mathbf{( \mathbf { A } / \mathbf { s } )}$ & $\mathbf{( n m )}$ & $\mathbf{( e V )}$ \\
\hline \hline Film A & 0.20 & 426 & 2.91 \\
\hline Film B & 0.15 & 521 & 2.38 \\
\hline Film C & 0.08 & 613 & 2.02 \\
\hline
\end{tabular}




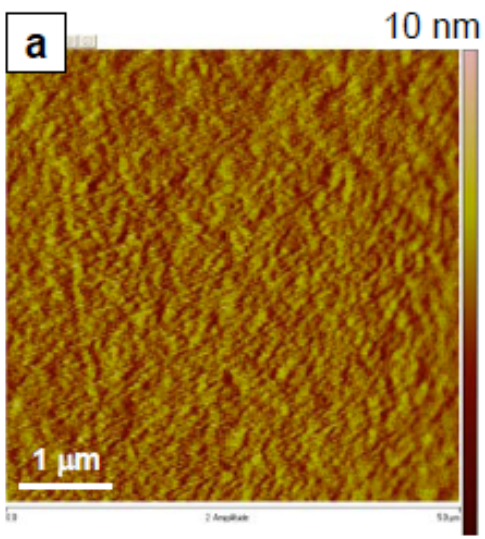

$-10 \mathrm{~nm}$

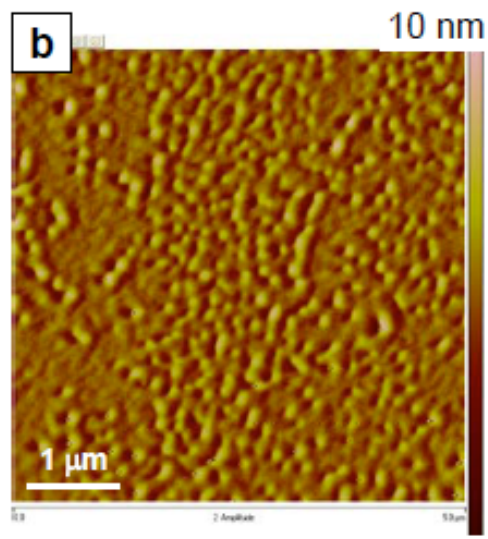

$-10 \mathrm{~nm}$

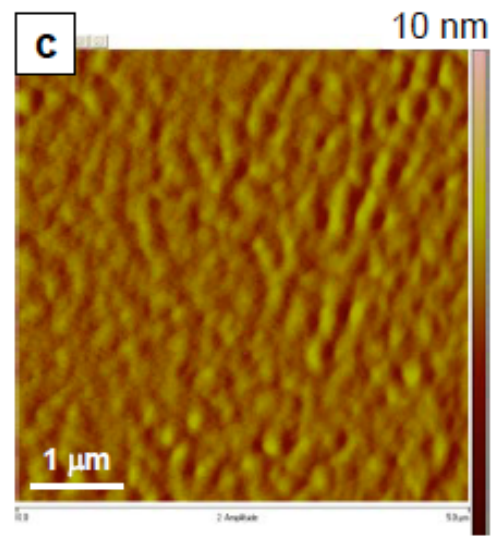

$-10 \mathrm{~nm}$
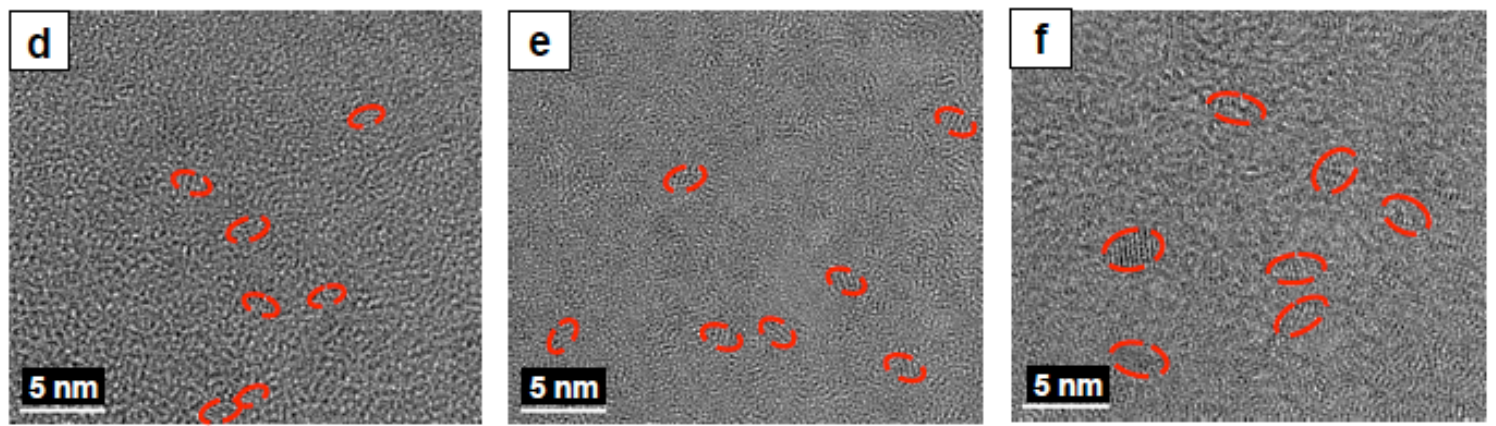

Figure 2: (a) AFM image of the Film A, (b) Film B and (c) Film C, (d) TEM image of the Film A, (e) Film B and (f) Film C.

Table 1 shows the summary of these ZnS thin films characteristics. It could be seen that the maximum photoluminescence energy of ZnS thin films decreased with the decreasing deposition rate, along with the changing the emission color from blue to red.

Figure 2a shows the AFM images of ZnS thin films deposited at different rate. It could be seen in Figure $\mathbf{2} \mathbf{a}$ that some clusters with small size existed in the Film A. More and more large clusters appear in Film B (Figure 2b) and Film C (Figure 2c). The average cluster size in Film $A, B$ and $C$ were measured to $183 \mathrm{~nm}, 207 \mathrm{~nm}$ and $314 \mathrm{~nm}$ respectively. Namely, the average cluster size grew bigger with the decrease of the deposition rate. The ZnS thin films with smooth surface were obtained at all deposition rates although several clusters of ZnS particles were observed. In addition, the surface roughness was analyzed by AFM images as well. The root mean square surface roughness of Film $A$ was 2.0 $\mathrm{nm}$, Film B was $2.3 \mathrm{~nm}$ and Film C was also $2.3 \mathrm{~nm}$, respectively. Therefore, all thermal evaporated films had almost same surface roughness without depending on the deposition rate.

The TEM image of $\mathrm{ZnS}$ thin films are shown in Figure $\mathbf{2 d}$, $\mathbf{e}$ and $\mathbf{f}$. The $\mathrm{ZnS}$ nanocrystallites could be seen in the TEM images, however a fraction of ZnS was not crystalline but amorphous. Several crystal fringes could be identified and measured. The average crystallite size of $\mathrm{ZnS}$ in Film A, B and $C$ were estimated to $1.6 \mathrm{~nm}, 1.8 \mathrm{~nm}$ and $2.5 \mathrm{~nm}$.
Therefore, the ZnS cluster was the aggregation of approximately $100 \mathrm{ZnS}$ nanocrystallites.

In order to compare the difference of deposition process and verify the emission mechanism, thin film was deposited by sputtering process with $0.20 \AA / s$ as the same deposition rate of thermal evaporation. The sputtered film thickness was 4.0 $\mathrm{nm}$. Figure 3 shows the TEM image of $\mathrm{ZnS}$ thin films

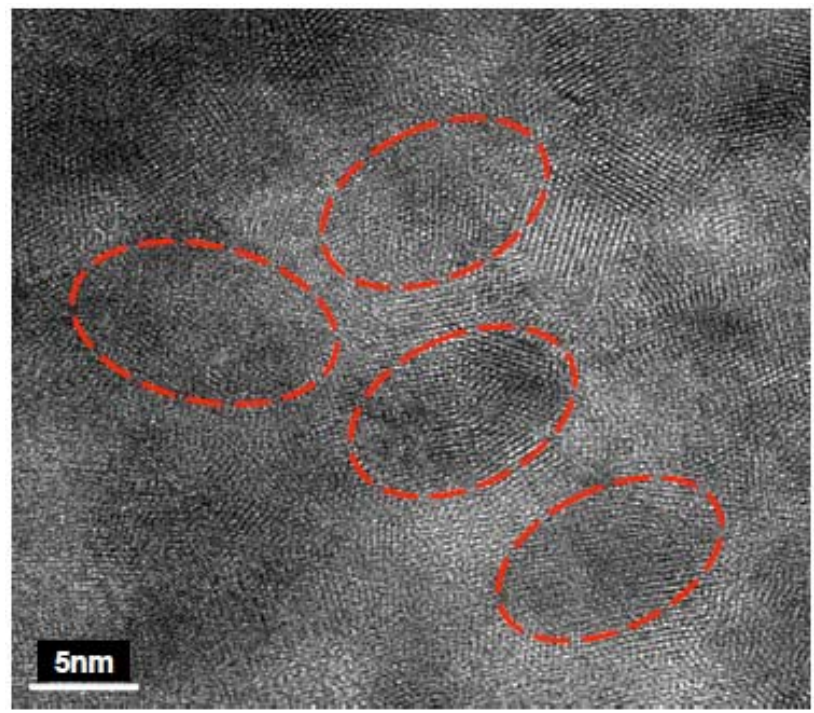

Figure 3: TEM image of ZnS deposited by sputtering. 
deposited by sputtering process. Compared to the thermal evaporated $\mathrm{ZnS}$ thin films, the larger crystal fringes could be seen clearly and the grain size was estimated to $9.1 \mathrm{~nm}$, which was 4 to 5 times bigger than the thermal evaporated ZnS thin films such as Film A, B and C. This was because sputtering method did not dissociate and fractionate $\mathrm{ZnS}$ to zinc and sulfur vapors and thus kept the crystalinity of $\mathrm{ZnS}$. In addition, the sputtered $\mathrm{ZnS}$ thin films did not emit any colors under UV irradiation (data not shown). This meant dissociation and fractionation of ZnS powder was essential to obtain the emission, and it was important that the grain sizes of $\mathrm{ZnS}$ particles in the films were small.

Figure 4 shows the TEM/EDS analysis of $Z n S$ thin films deposited by thermal evaporation with fast deposition rate and sputtering process with same deposition rate as the thermal evaporation process. The intensity of zinc and sulfur peaks was not as strong in the spectrum of $\mathrm{ZnS}$ deposited by thermal evaporation. In addition, the peak of oxygen atom could be confirmed. On the other hand, sputtered ZnS thin films with superior crystallinity had stronger peaks of zinc and no oxygen peak. The difference between the thermal evaporated and sputtered ZnS was supposed to be their crystallinity and incorporation of oxygen atoms.
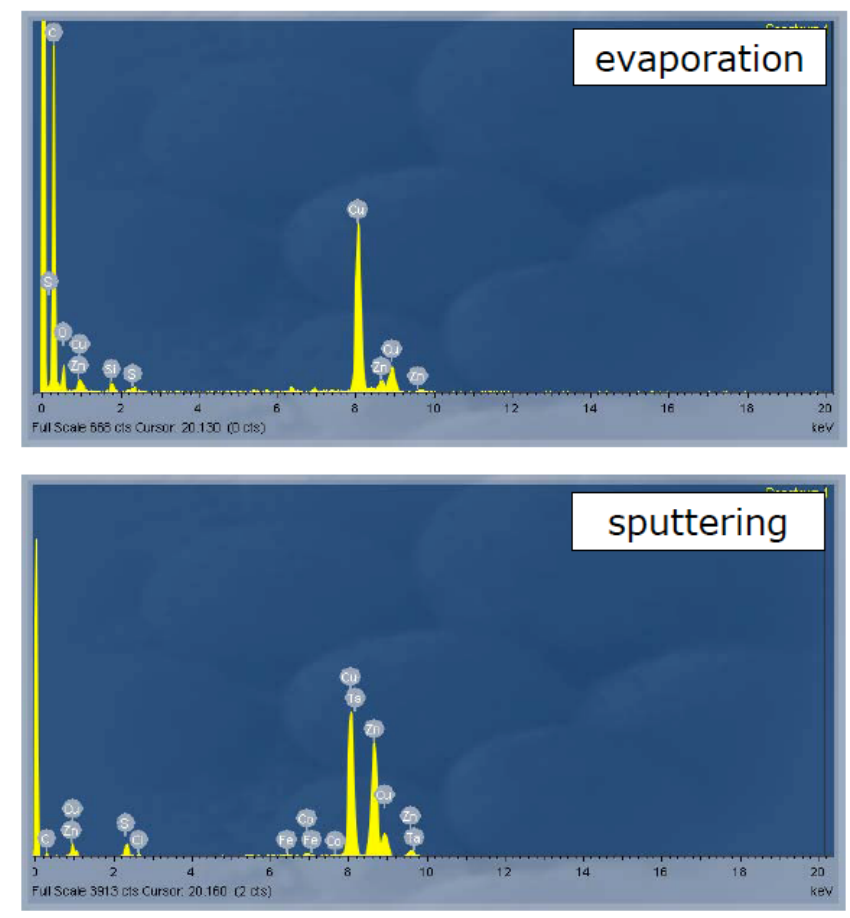

Figure 4: TEM/EDS analysis of ZnS thin films.

The thermal evaporated $\mathrm{ZnS}$ thin films had small nanocrystallites, which might indicate the characteristics of quantum dots. However, according to the research by Brus [1], the energy of quantum dots is calculated using following equation.

$E_{g}($ quantum dot $)=E_{g}($ bulk $)+\frac{h^{2}}{8 R^{2}}\left(\frac{1}{m_{e}}+\frac{1}{m_{h}}\right)-\frac{1.8 e^{2}}{4 \pi \varepsilon_{0} \varepsilon R}$
Here, $E_{g}$ is the band gap energy of a quantum dot or bulk material, $R$ is a radius of a quantum dot, $m_{e}$ is the effective mass of the electron, $m_{h}$ is the effective mass of the hole, $\varepsilon$ is the dielectric constant and $\varepsilon_{0}$ is the permittivity of the vacuum. This means the band gap energy of quantum dot is more than that of bulk state. In the case of $\mathrm{ZnS}$, its band gap energy of bulk state is from $3.7 \mathrm{eV}$ to $3.8 \mathrm{eV}$ depending on the crystal structure and the band gap energy of $\mathrm{ZnS}$ quantum dots become larger than $3.8 \mathrm{eV}$ as the diameter of $\mathrm{ZnS}$ particle size decreases. This means $\mathrm{ZnS}$ does not show the emission within the visible range of wavelength at room temperature. On the other hand, our thermal evaporated $\mathrm{ZnS}$ samples showed several emission within the visible range, which indicated that the other mechanism of light emission existed beside the quantum confinement effect. The optical light emission of $\mathrm{ZnS}$ thin films are assumed to be attributed to localize lattice defects or impurities of ZnS crystals such as Schottky defect and the replacement sulfur atoms with oxygen atoms [15]. In our experiment, the $\mathrm{ZnS}$ thin films were deposited on the $\mathrm{Cu}$ grid to make a TEM measurement. Transition elements such as $\mathrm{Co}$, $\mathrm{Ta}$ and $\mathrm{Fe}$ were not assumed to affect the emission of $\mathrm{ZnS}$ in the thermal evaporated films. The replacement of sulfur with oxygen and several vacancies of zinc and sulfur atoms should alter the strain to the lattices, which was supposed to result in the light emission. These vacancies and replacement might have occurred during the thermal evaporation, namely dissociation and fractionation of $\mathrm{ZnS}$ resulted in these defects in the $\mathrm{ZnS}$ crystals. The emitting color differences from these localized defects were presumed to be caused from the additional effect of variations grain size of $\mathrm{ZnS}$. One possibility is that the degree of stress in the crystallites depends on size and that this stress shifts the emission color. A second possibility is that the smaller ZnS nanocrystallites have a larger photoluminescence energy in which the localized defect has an emission color of blue. In contrast, the larger size of ZnS nanocrystallites has smaller photoluminescence energy within which the localized defect emission shifts red.

\section{CONCLUSION}

The ZnS thin films were deposited by thermal evaporation process of ZnS bulk powder. Within the predominately amorphous films, nanocrystallites having dimensions in the range of $1 \mathrm{~nm}$ to $3 \mathrm{~nm}$ were observed by TEM.

By controlling the deposition rate, the position in or the maximum in the photoluminescence spectra could be easily tuned from 2.9 to $2.0 \mathrm{eV}$. Since these energies are lower than that of bulk $\mathrm{ZnS}$, quantum confinement effect is not the sole cause of the observed tunability. The $\mathrm{ZnS}$ thin film emitting red with small photoluminescence energy was obtained as the deposition rate decreased. On the other hand, the large photoluminescence energy with blue emission was obtained with increase of the deposition rate. The changes in optical 
properties are potentially attributable to the lattice defects of ZnS crystals such as Schottky defect and the replacement sulfur atoms with oxygen atoms.

The color of light emission was obtained by controlling the deposition rate of $\mathrm{ZnS}$. We believe that the thermal evaporation with controlling the deposition rate for $\mathrm{ZnS}$ thin films is one of the candidates to obtain the emitting thin films for applying to a display and solid state lighting.

\section{ACKNOWLEDGEMENT}

The authors would like to thank Dr. Dong Soo Yun for the TEM measurement and Showa Denko K. K. for the financial supports.

\section{REFERENCES}

[1] Brus LE. Electron-electron and electron-hole interactions in small semiconductor crystallites: The size dependence of the lowest excited electronic state. J Chem Phys 1984; 80: 4403-9. http://dx.doi.org/10.1063/1.447218

[2] Yan J, Fang XS. Zhang LD, Bando Y, Gautam UK, Dierre B, Sekiguchi T, Golberg D. Structure and Cathodoluminescence of Individual ZnS/ZnO Biaxial Nanobelt Heterostructures. Nano Lett 2008; 8: 2794-9. http://dx.doi.org/10.1021/nl801353c

[3] Zhu G, Zhang S, Xu Z, Ma J, Shen X. Ultrathin ZnS Single Crystal Nanowires: Controlled Synthesis and Room-Temperature Ferromagnetism Properties. J Am Chem Soc 2011; 133: 15605-12. http://dx.doi.org/10.1021/ja2049258

[4] Tain Y, Huang G-F, Tang L-J, Xia M-G, Huang W-Q, Ma Z-L. Sizecontrollable synthesis and enhanced photocatalytic activity of porous ZnS nanospheres. Mater Lett 2012; 83: 104-7. http://dx.doi.org/10.1016/i.matlet.2012.05.134

[5] Wanga $H$, Chenb Z, Chenga Q, Yuan L. Solvothermal synthesis and optical properties of single-crystal $\mathrm{ZnS}$ nanorods. J Alloys Comp 2009; 478: 872-5.

http://dx.doi.org/10.1016/i.jallcom.2008.12.039
[6] Fang XS, Le CH, Zhang LD, Wang YH, Wu YC. TemperatureControlled Catalytic Growth of ZnS Nanostructures by the Evaporation of ZnS Nanopowders. Adv Funct Mater 2005; 15: 63-8. http://dx.doi.org/10.1002/adfm.200305008

[7] Yuan HJ, Xie SS, Liu DF, Yan XQ, Zhou ZP, Ci LJ, Wang JX, Gao Y, Song L, Liu LF, Zhou WY, Wang G. Formation of ZnS nanostructures by a simple way of thermal evaporation. J Cryst Growth 2003; 258: 225-31.

http://dx.doi.org/10.1016/S0022-0248(03)01502-1

[8] Ghosh PK, Chattopadhyay KK. Optical properties of ZnS nanoparticles synthesized by Rf-magnetron sputtering technique. AIP Conference Proceedings, 2013; 1536: 23-4. http://dx.doi.org/10.1063/1.4810081

[9] Grün M, Storzum A, Hetterich M, Kamilli A, Send W, Walter Th, Klingshirn C. J Cryst Growth 1999; 201/202: 457-60. http://dx.doi.org/10.1016/S0022-0248(98)01375-X

[10] Wei A, Liu J, Zhuang M, Zhao Y. Preparation and characterization of ZnS thin films prepared by chemical bath deposition. Mat Sci Semicon Proc 2013; 16: 1478-84. http://dx.doi.org/10.1016/j.mssp.2013.03.016

[11] Tokuda T, Yoshino K. Growth and characterization of ZnS films by spray pyrolysis. Phys Status Solid C 2013; 10: 1102-6. http://dx.doi.org/10.1002/pssc.201200828

[12] Pulker HK, Jung E. Correlation between film structure and sorption behaviour of vapour deposited ZnS, cryolite and MgF2 films. Thin Solid Films 1971; 9: 57-66. http://dx.doi.org/10.1016/0040-6090(72)90330-6

[13] Murray CB, Kagan CR, Bawendi MG. Self-Organization of CdSe Nanocrystallites into Three-Dimensional Quantum Dot Superlattices. Science 1995; 270: 1335-8

http://dx.doi.org/10.1126/science.270.5240.1335

[14] Grover R, Srivastava R, Rana O, Srivastava AK, Maurya KK, Sood $\mathrm{KN}$, Mehta DS, Kamalasanan MN. Electroluminescence from hybridorganic LEDs based on thermally evaporated CdS thin films. J Lumin 2012; 132: 330-6.

http://dx.doi.org/10.1016/i.jlumin.2011.08.021

[15] Denzler D, Olschewski M, Sattler K. Luminescence studies of localized gap states in colloidal ZnS nanocrystals. J Appl Phys 1998; 84: $2841-5$.

http://dx.doi.org/10.1063/1.368425

(c) 2014 Urakawa and Gleason; Licensee Lifescience Global.

This is an open access article licensed under the terms of the Creative Commons Attribution Non-Commercial License (http://creativecommons.org/licenses/by-nc/3.0/) which permits unrestricted, non-commercial use, distribution and reproduction in any medium, provided the work is properly cited. 